\title{
Radiology Case Reports
}

Volume 9, Issue 3, 2014

\section{Intrahepatic ovulation}

\author{
Artur L. Wozniak, HBSc; Kari L. Visscher, MD, MScBMC; and Mousumi Bhaduri, MBBS, DMR, \\ DNB, DABR
}

Ectopic ovaries are a rare finding in the literature, with fewer than 50 published cases to date. This phenomenon has been found in the omentum, bladder, mesentery, uterus; attached to the colon; inside the left labia majora; and in the kidney. Various etiologies have been proposed, including postsurgical or postinflammatory transplantation, malignant origins, and abnormal embryologic development. We report the ultrasonographic, computed tomographic (CT), and magnetic resonance (MR) imaging of, what is to the best of our knowledge, the first case of an intrahepatic ectopic ovary.

\section{Case report}

A 26-year-old woman, gravida 0, was referred for assessment of recurrent right-lower-quadrant pain since puberty with menstrual irregularity. Her history was significant for spina bifida and cloacal extrophy, for which she had multiple reconstructive procedures. Past surgical history included excision and closure of an omphalocele; reconstruction of the bladder, urethra, and vagina; construction of an end-sigmoid colostomy; and correction of a lipomeningocele, with multiple surgical complications.

Physical examination revealed a tender right lower quadrant. Ultrasound demonstrated a single ovary located in the left hemipelvis, along with a right pelvic kidney and uterus didelphys. Ultrasound also showed a $2.3 \times 3.0 \times 5.7 \mathrm{~cm}$ (transverse $\mathrm{x}$ anteroposterior $\mathrm{x}$ sagittal) mass consisting of multiple small cysts in segment VI of the liver, with blood flow separately from the aorta and IVC (Fig. 1). As the renal function was poor, a noncontrast CT scan for further characterization was done, which showed a nonspecific cystic/hypodense mass invaginating into the right lobe of the liver (Fig. 2). An MRI with contrast redemonstrated this

Citation: Wozniak AL, Visscher KL, Bhaduri M. Intrahepatic ovulation. Radiology Case Reports. (Online) 2014;9(3);945.

Copyright: $\odot 2014$ The Authors. This is an open-access article distributed under the terms of the Creative Commons Attribution-NonCommercial-NoDerivs 2.5 License, which permits reproduction and distribution, provided the original work is properly cited. Commercial use and derivative works are not permitted.

Mr. Wozniak is a medical student, Dr. Visscher is a Radiology Resident, Dr. Bhaduri is an Assistant Professor in the Department of Medical Imaging, all at the Schulich School of Medicine and Dentistry, University of Western Ontario, Longon, ON, Canada. Contact Dr. Bhaduri at Mousumi.bhaduri@lhsc.on.ca.

Competing Interests: The authors have declared that no competing interests exist. DOI: $10.2484 /$ rcr.v9i3.945

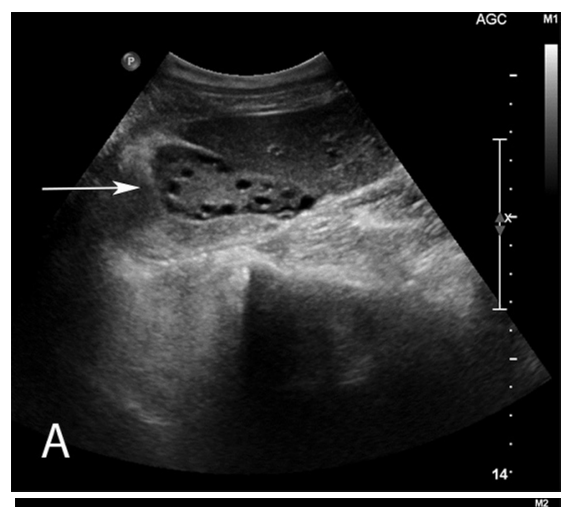

Figure 1. Sagittal $(A)$, axial (B), and Doppler ultrasound (C) demonstrate a multicystic mass surrounded by the liver. The morphological appearance of the mass is similar to that of an ovary.

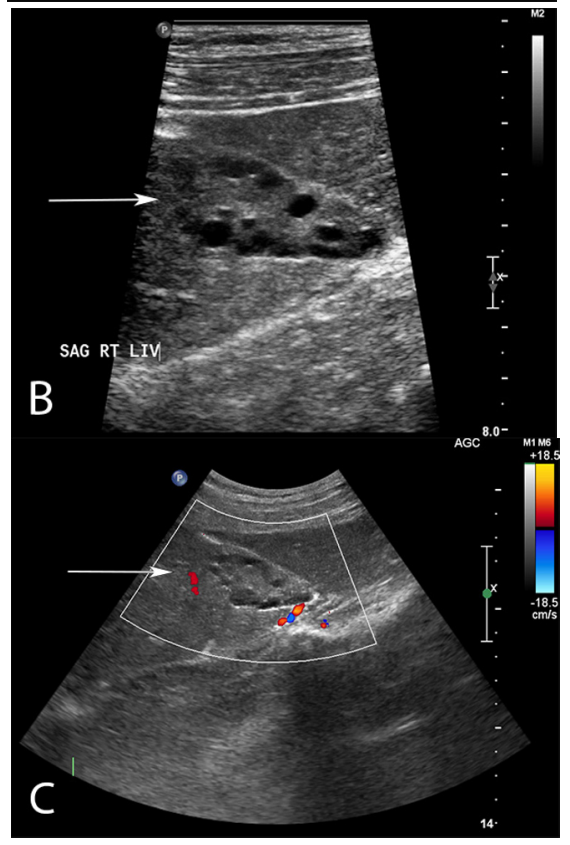




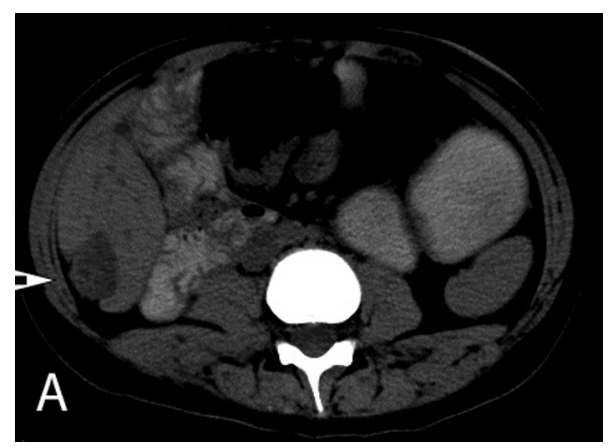

Figure 2. Axial (A) and coronal (B) noncontrast CT of the abdomen demonstrates a nonspecific hypodense mass within the liver.

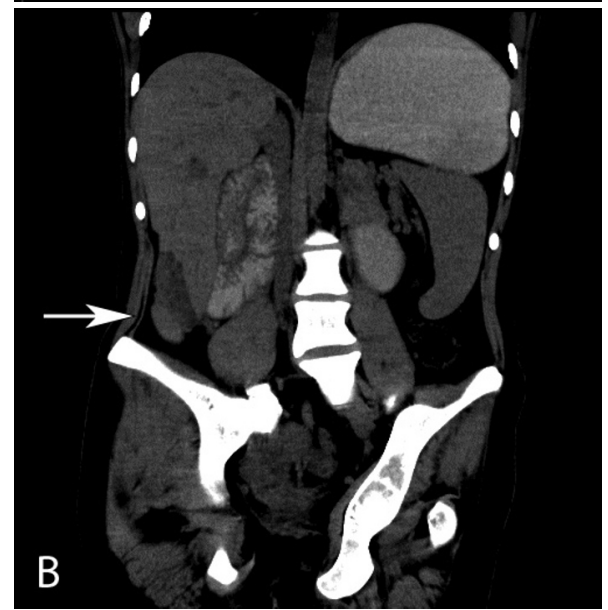

multicystic mass that appeared morphologically similar to an ovary (Fig. 3). The left ovary was identified in its expected location. These findings, in combination with an absent right pelvic ovary, were most consistent with an intrahepatic ectopic ovary.

\section{Discussion}

According to recent literature, the role of highresolution, real-time ultrasonography in the diagnosis of ectopic ovarian tissue in inguinal hernias has been growing (1). However, complete ectopic ovaries are uncommon, with fewer than 50 cases reported in the literature to date, and they are rarely identified through ultrasonography alone. It is unknown whether the infrequency of such occurrences is caused by a low incidence or lack of detection due to nonspecific symptoms or asymptomatic patients (2). Occurrence of ovarian tissue within the parenchyma of another organ has been reported, only twice, with both cases being intrarenal $(3,4)$. Our case marks the first intrahepatic ectopic ovary.

Ectopic ovaries have been the basis of controversy in terms of naming, classifying, and identifying their etiology $(5,6)$. In this report, we use the convention chosen by Litos et al, which states that the term "ectopic ovary" is used for ovaries that are found outside of their normal position, with an undetermined cause, and where there is no additional ovarian tissue. This is in contrast to supernumerary ovaries, which are present in addition to two normal ovaries (6). In terms of etiology, several hypotheses include postsur-
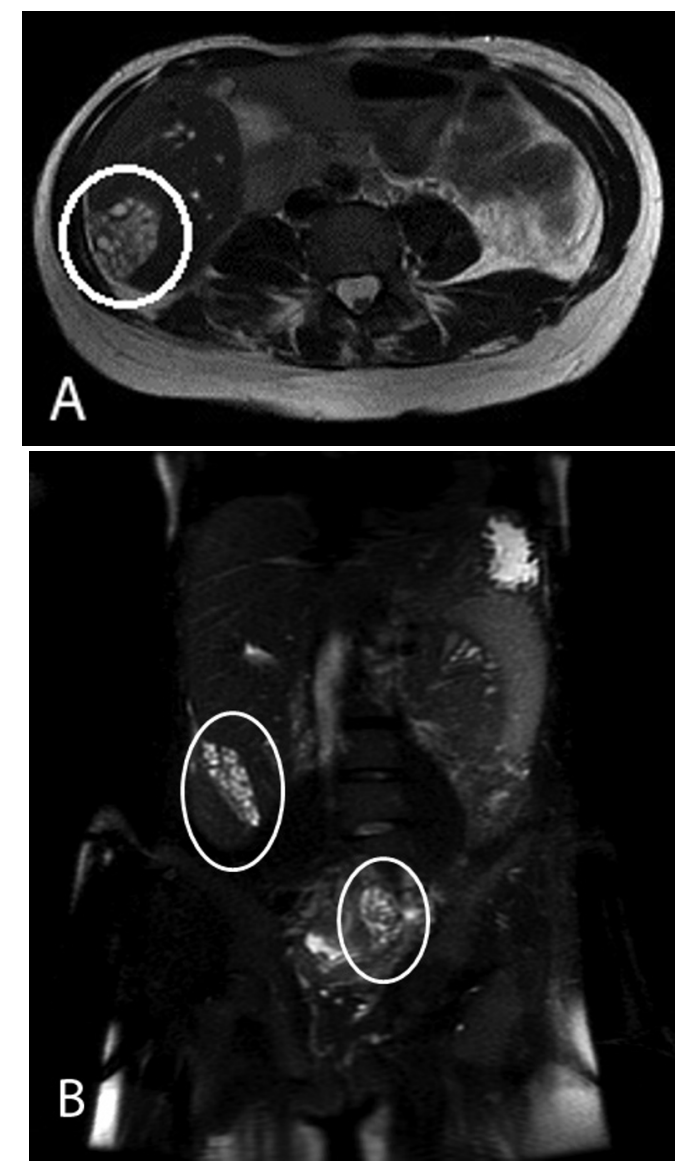

Figure 3. MRI of the abdomen. T2-weighted axial (A) and coronal (B) images demonstrate a morphological ectopic right ovary invaginating into the right lobe of liver, similar in appearance to the left ovary (circled on coronal T2WI) with no significant postcontrast enhancement.

gical or postinflammatory implantation, spontaneous generation as part of a malignancy, or abnormal embryonic development (5, 7-9). For this case, both embryonic development and transplantation are possible etiologies.

In normal embryonic development, the ovaries arise from two cell lines:

* Cells of the mesoderm of the germinal ridge that arise from the medial segment of the intermediate cell mass

* Oocytes that migrate to the genital ridge along the mesentery of the hind gut before migrating caudally to the pelvic cavity and their normal position (10)

Embryological ectopic ovaries can arise either from sequestration of cells of the genital ridge, or arrest of the migration of the oocytes that leads to differentiation of surrounding tissue (8-10). The former is most likely in this case, as there is no right ovary in the expected anatomical location. This hypothesis is strengthened by evidence that ectopic ovaries are associated with genitourinary tract malformations such as renal agenesis and uterine malforma- 
tions, which our case exhibits (11). However, this leads to the question, how did these cells migrate superiorly to the developing liver? In our case, there are two possible mechanisms: the omphalocele, leading to contact at an early stage of development between the liver and oocytes and/or the multiple surgeries secondary to the multiple congenital anomalies.

The surgical scenario is supported by evidence in animal models that surgically detached and autotransplanted ovarian tissue may be functional in its new environment (12). Further evidence also suggests that scar tissue is more susceptible to implantation than normal tissue (13). This, coupled with the extensive reconstructive surgeries shortly after birth for the omphalocele, bladder, urethra, and genital abnormalities, may have resulted in incidental postsurgical transplantation of ovarian tissue onto a compromised region of the liver, allowing for development of a functional intrahepatic ovary.

At this time, it is unknown what treatment if any should be proposed for the intrahepatic ectopic ovary. The main considerations would be the recurrent abdominal pain and the fact that, rarely, cases of ectopic ovary may develop neoplasms, such as cystic teratomas or cystadenomas (14). Despite this, the patient chose not to excise the ectopic ovary.

This case demonstrates the importance of considering ectopic ovarian tissue in differential diagnosis when presented with a multicystic mass and cyclical abdominal pain in an individual with multiple genitourinary and gastrointestinal malformations. For this patient, four separate scans over several weeks were completed when ultrasound with Doppler may have sufficed, thus saving this patient time and undue stress.

\section{References}

1. Machiels F, De Maeseneer M, Desprechins B, Casteels A, De Backer A, Osteaux M. Unusual location of an ovary: ultrasonographic features and surgical correlation. 7 Belge Radiol 1998 Dec; 81(6):288. [PubMed]

2. Cohen JA, Holzman L. A giant ectopic ovary. J Laparoendosc Adv Surg Tech A 2001 Jul; 11 (1): 31-5. DOI: 10.1089/10926420150502913

3. Levy B, DeFranco J, Parra R, Holtz P. Intrarenal supernumerary ovary. 7 Urol 1997 Jun; 157(6): 2240-1. [PubMed]

4. Hartigan K, Pecha B, Rao G. Intrarenal supernumerary ovary excised with partial nephrectomy. Urology 2006 Feb; 67(2): 424.e11-2. [PubMed]

5. Vendeland LL, Shehadeh L. Incidental finding of an accessory ovary in a 16 year old at laparoscopy. A case report. $\mathcal{J}$ Reprod Med 2000 May; 45(5): 435-8. [PubMed]

6. Litos MG, Furara S, Chin K. Supernumerary ovary: A case report and literature review. 7 Obstet Gynaecol. 2003 May; 23(3): 325-7. [PubMed]

7. Lachman MF, Berman MM. The ectopic ovary, a case report and review of the literature. Arch Pathol Lab Med 1991 Mar; 115(3): 233-5. [PubMed]

8. Cruikshank S. Supernumerary ovary: embryology. Int 7 Gynaecol Obstet 1991 Feb; 34(2): 175-8. [PubMed]

9. Printz JL, Choate JW, Townes PL, Harper RC. The embryology of supernumerary ovary. Obstet Gynecol, 1973 Feb; 41(2): 246-2. [PubMed]

10. Badawy SZA, Kasello DJ, Powers C, Elia G, Wojtowycz AR. Supernumerary ovary with an endometrioma and osseous metaplasia: A case report. Am 7 Obstet Gynecol 1995 Nov; 173(5): 1623-4. [PubMed]

11. Poma PA. Supernumerary ovary. IMJ Ill Med J.1982 Jul; 162(1): 34-35. [PubMed]

12. Shemwell RE, Weed JC. Ovarian remnant syndrome. Obstet Gynecol 1970 Aug; 36(2): 299-303. [PubMed]

13. Camilleri AP, Micallef T, Ellul J, Said J. Homograft transplantation of the ovary. Transplantation 1976 Sep; 22(3): 308-11. [PubMed]

14. Besser M, Posey D. Cystic teratoma in a supernumerary ovary of the greater omentum. 7 Reprod Med 1992 Feb; 37(2): 189-193. [PubMed] 